Texas A \& M Univ.

(16) Sandmeir, H.A., et al.: Nucl. Sci. Eng., 3, 315 (1965).

(17) Chezem, C.G., et al.: Pulsed neutron analysis in the Los Alamos coupled reactor experiment, $L A-3263-M S$, (1965).

(18) GAGE, S.J.: Investigations on the dynamic behavior of coupled core nuclear reactors, Ph. D. Thesis Purdue Univ., (1965).

(19) Hophins, G.C.: Transfer functions and response for coupled core reflector systems, Proc. Conf. Coupled Reactor Kinetics, 42, (1967). Texas A \& M Univ.,
(20) GAGE, S.J.: Numerical analysis of physically realistic coupling models, ibid., 230 (1967).

(21) DANOFSKy, R.A., et al.: Nucl. Sci. Eng., 15, 131 (1963).

(22)海老㴍街衛, 古市憲二: 結合炉パラメータの時間 依存，本会昭43年会要旨集，A7，(1968).

(23) VARgA, R.S.: "Matrix Iterative Analysis", (1962), Prentice-Hall.

(24) Teffers, D.E., et al.: Flux tilting in a two zone reactor, Nucl. Sci. Eng., 31, 358 (1968).

(25) Gunson, W.H., et al.: Transient response of coupled fast reactor cores, $A N L-7120,776$ (1966).

\title{
研究論文
}

\section{2. 円柱炉心における高温点係数の研究}

\section{宮 本 喜 戟*}

\author{
(1969年 10 月 8 日 受理)
}

\section{Study of Hot Spot Factor for Cylindrical Cores}

By Yoshiaki MIYAMOTO

\begin{abstract}
In the reactor core, there are produced a number of hot channels or hot spots. A discussion is given: on the probability that no hot channel or hot spot exceeds a maximum value. By means of the probability multiplication formula, it is clarified that the number of hot spots is related to the nonfailure probability. A method for analyzing the hot spot factor is proposed for cylindrical cores. The method is presented in the form of diagrams, so as to be readily applicable to the thermal design of reactor cores. Given a requirement for the nonfailure probability to be $99.87 \%$ with a cylindrical core, the number of hot spots is related to a confidence level coefficient at the core center and this relation is shown in diagrams.
\end{abstract}

\section{I 、緒言}

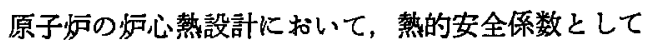
用いられるホットチャンネル・ファクタまたはホット スポット・ファクタは, 普通, ある1点に対する確率で ある。しかし炻心の中で高温になる所は複数個存在す る。したがって，炉心全体から見た高温点の確率を論 ずる方がより論理的な設計である。

Judge ら等しい確率を有するホットチャンネル が複数個の場合の“effective”ホットチャンネル・フォ
クタについて述べている。さらに出力が cosine 分布で ある場合の例について，同し確率を有する“effective”な 個数に变換している(2)。また, Amedola ${ }^{(3)}$ は付加的な shape factor を設けてその取扱いを述へている。しか し，これらの取扱いは特殊であり，設計を行う上で用 いにくい。

本報は(2)式で定義される高温点係数について, 複 数個の高温点を有する場合を考察する。具体例とし

* 日本原子力研究所 (Japan At. Energy Res. Inst.) 
て，円柱炻心に対する複数個の高温点の確率解析法を 提案して，設計使用しやすいようにとの式を図表に する。さらに，炉心全体の高温点が，ある最大值を越 えない確率が 99.87\%になるための炉心中心の高温点 係数を求める。

\section{II. 高温点係数}

\section{1. 単一の高温点に対する高温点係数}

炉心の注目点の温度差 ${ }^{*}$ は, 变数 $x_{1}, x_{2}, \cdots, x_{n}$ の関数 になっている。

$$
\Delta t=f\left(x_{1}, x_{2}, \cdots, x_{n}\right)
$$

ここで，それぞれの変数はバラッキ(不確かさ)が考え られる。いま，この変数がそれぞれ独立に正規分布を なすと考克ると，(1)式から $\Delta t$ は近似的に正規分布 L, $\Delta t$ がある值(高温点温度差 $\Delta t_{H s}$ )を越えない確率 を容易に得ることができる。

いま，変数の亚均值を $\bar{x}_{1}, \bar{x}_{2}, \cdots, \bar{x}_{n}$ とすれば，公称 温度差は $\Delta t_{N}=f\left(\bar{x}_{1}, \bar{x}_{2}, \cdots, \bar{x}_{n}\right)$ で表わされ，温度差の 標準偏差 $\sigma_{\iota}$ は $(1)$ 式を Taylor 展開して求めることが できる。高温点係数 $F_{H S}$ を次式のように定義すれば，

$$
F_{H S} \equiv \frac{\Delta t_{H S}}{\Delta t_{N}}=1+\lambda \frac{\sigma_{t}}{\Delta t_{N}}
$$

$\Delta t か ゙ \Delta t_{B S}$ を越えない確率は正規分布の信頼度を表わ す係数 $\lambda$ から求められる。ここで， $\lambda$ は次式で定義さ れる值で，数表化されている。

$$
\lambda=\frac{\Delta t_{Z S S}-\Delta t_{N}}{\sigma_{t}} \text { または } \frac{x_{\max }-\bar{x}}{\sigma_{x}}
$$

\section{2. 複数個の高温点の確率}

第 1 節で求めた高温点温度の確率は，炣心のある 1 点の確率に対するるのである。しかし，一般に师心内 の高温点は 1個所とは限らず任意の場所で考えるこ とができる。怔心内の各位置の高温点が互いに独立 で, 最大值 $A_{\mathrm{e}}$ を越光ない確率をそれぞれ $P_{1}, P_{2}, \cdots \ldots$. とし， $A_{\varepsilon}$ 存越え西確率をそれぞれ $U_{1}, U_{2}, \cdots \cdots$ とす る。ただし， $P_{1}=1-U_{1}, P_{2}=1-U_{2}, \cdots \cdots$ の関係があ る。炀心内のすべての高温点が最大值 $A_{\mathrm{c}}$ を越党ない 確率 $P_{\mathrm{c}}$ 虹乗法定理によって次式で表わされる(ら)。

$$
P_{c}=P_{1} \cdot P_{2} \cdots \cdot P_{N}=\prod_{k=1}^{N} P_{k}
$$

また， $P_{\mathrm{o}}$ を最大值を越える確率で表わせば，

$$
P_{c}=\prod_{k=1}^{N}\left(1-U_{k}\right) \doteqdot 1-\sum_{k=1}^{N} U_{k}
$$

ここで, $U_{k}$ は非常に小さいとして高次項を省略してあ る。いますずての高温点が最大值を越光ない確率 (越える確率)が同じであるとすれば，（4）式办ら

$$
P_{o}=P_{1}^{N}
$$

または，(5)式から炏式で表わされる。

$$
P_{\mathrm{c}} \doteqdot 1-N U_{1}
$$

各高温点の確率を正規分布として，同じ確率を有する

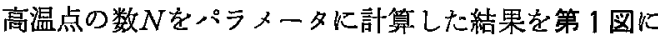
示す。この図から明らかな上 5 に $N=1$ 以外の確率 は正規分布ではない。

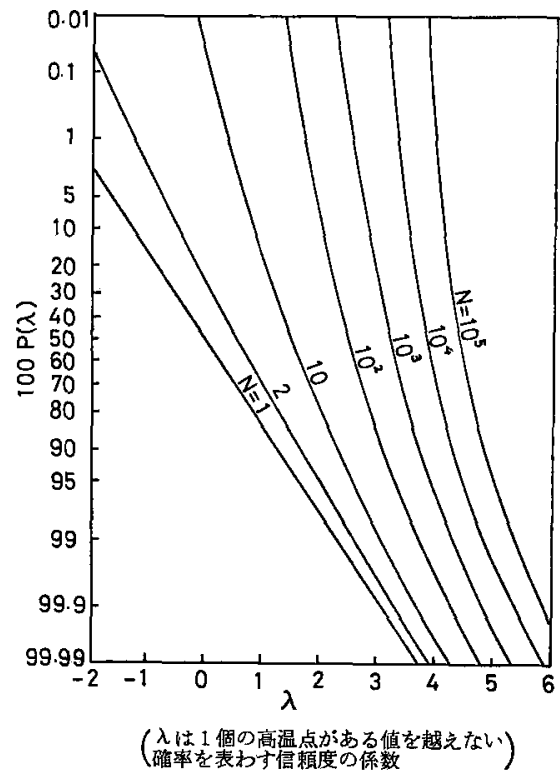

第1图 ある值を越えない1個の高温点の 確率々等しい確率を持つ高温点の 複数個の確率

\section{III. 円柱炉心の高温点の確率と高温点係数}

\section{1. 円柱炉心の高温点の確率}

円柱炉心の半径方向の出力分布は $J_{0}$ 分布であるが， 近似的に次式で表わされる。

$$
\Phi=\Phi_{0}\left[1-\left(\frac{r}{R}\right)^{2}\right]
$$

ここで, $\Phi_{0}: r=0$ K捕ける出力, $R:$ 炻心外描半径 いま（7)式で表わされる梮心の高温点の確率を求 めるため，円柱を $\Delta r$ の間隔で円環を作る。 $i$ 番目の円 環にある高温点の数を $n_{\imath}$ ，その 1 個の高温点が最大值 越光ない確率を $P\left(\lambda_{i}\right)$ とすれば，忟心全体で最大值 $\Phi_{c}$ を越光ない確等 $P_{\mathrm{c}}$ は $(4)$ 式と(6)式を適用して次 式で表わされる。

* 注目点は亦る温度を求め上らとする揚所のことで ある。温度差は注目点の温度と，古る基华の温度 との差である。 


$$
\begin{array}{r}
P_{\mathrm{c}}=P^{n_{0}}\left(\lambda_{0}\right) \cdot P^{n_{1}}\left(\lambda_{1}\right) \cdots \cdots \cdots \cdot P^{n_{i}}\left(\lambda_{i}\right) \\
こ こ \tau ゙, \quad \lambda_{i}=\frac{\Phi_{c}-\Phi_{i}}{\sigma_{i}}=\frac{1}{\left(\sigma_{i} / \Phi_{i}\right)}\left[\frac{\Phi_{c}}{\Phi_{i}}-1\right]
\end{array}
$$

(8)式の対数をとれば,

$$
\ln P_{c}=\sum_{i=0} n_{i} \ln P\left(\lambda_{i}\right)
$$

炉心半径を $r_{\mathrm{e}}$, 炉心全体の高温点数を $N$ とすれば, $n_{i}=2 N r \Delta r / r_{c}^{2}$ となるから，上式は次式で表わされる。

$$
\ln P_{\mathrm{c}}=\frac{2 N}{r_{\mathrm{e}}^{2}} \sum_{1} r \ln P\left(\lambda_{i}\right) \Delta r
$$

円柱の分割数を増せば，

$$
\ln P_{\mathrm{c}}=\frac{2 N}{r_{c}^{2}} \int_{0}^{r_{\mathrm{c}}} r \ln P\left(\frac{\frac{\Phi_{c}}{\Phi_{0}}-\left\{1-\left(\frac{r}{R}\right)^{2}\right\}}{\frac{\sigma_{0}}{\Phi_{0}}\left\{1-\left(\frac{r}{R}\right)^{2}\right\}}\right) d r
$$

$r=r_{\mathrm{c}} u$ なる変換を行えば，(9)式は次式で表わされる。

$$
\frac{\ln P_{c}}{2 N}=\int_{0}^{1} u \ln P\left(\frac{\lambda_{0}\left(\frac{\sigma_{0}}{\Phi_{0}}\right)+\left(\frac{r_{c}}{R} u\right)^{2}}{\frac{\sigma_{0}}{\Phi_{0}}\left\{1-\left(\frac{r_{c}}{R} u\right)^{2}\right\}}\right) d u
$$

ここで， $\lambda_{0}, \sigma_{0}$ はそれぞれ $r=0$ の信頼度を表わす係数 扰よび標準偏差である。(10)式の $r_{\mathrm{o}} / R, \sigma_{0} / \Phi_{0}$ をパラメ 一夕に $\ln P_{t} / 2 N$ と $\lambda_{0}$ との関係を第 2 図に示す。四中 の $r_{c} / R=0$ 岋 $\Phi_{i}=\Phi_{0}$ k相当し, すべての高温点で同 じ確率を有する(6)式を表わす。また第 3 図(a) (d)K は $\lambda_{0}$ をパラメータに $\ln P_{c} / 2 N$ と $r_{c} / R$ との関係を示 す。

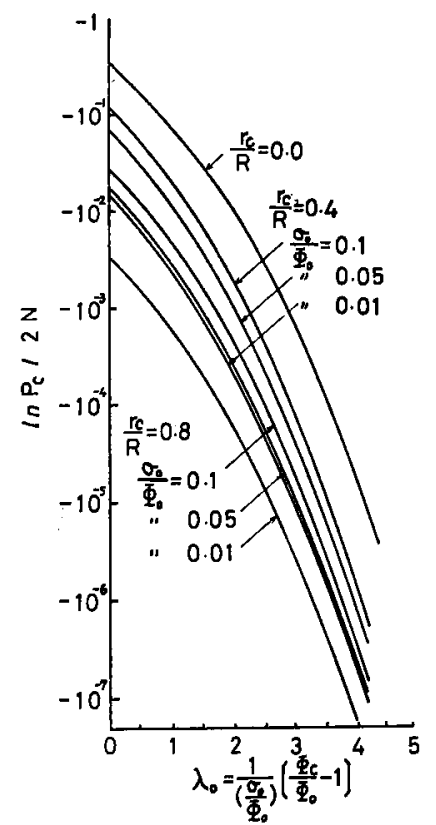

第 2 図 出力分布が $\Phi=\Phi_{0}\left[1-\left(\frac{r}{R}\right)^{2}\right]$ の確率

\section{2. 炉心の確率が $3 \sigma$ である高温点係数}

円柱师心の炉心全体から考点た，ある最大值を越え ない確率 $P_{c}$ を与えた場合，他のパラメータとの関係 恃(10)式加求められる。しかし，直接(10)式加ら求 めるのは困難であるため第 2 四から得る。たとえば， $P_{c}=0.9987$ ( 1 個の高温点が最大值を越えない確率の 信頼度の係数 $\lambda=3$ K相当する)《なるための炻心中心 の信賴度係数 $\lambda_{0}$ と高温点 $N$ との関係は第 4 図(a)，(b) に示される。したがって，円柱师心全体の確率が 0.9987になるためには, $r=0$ における信頼度保数 $\lambda_{0}$ を 同図から求め，そのときの高温点保数を(2)式から求 めればよい。

たとえば，円柱炡心の燃料温度差に対する高温点係 数について考劣る。炻心内の半径方向の出力分布之燃 料温度分布加等しいと仮定 L, $r_{c}=30 \mathrm{~cm}, R=45 \mathrm{~cm}$, $N=91 \times 61=5,551$, 杰心炻心中心の公称燃料最高温度 差は $\Delta t_{N}=1,682.1^{\circ} \mathrm{C}$, 標準偏差は $\sigma_{\ell} / \Delta t_{N}=0.052$ の関 係兮与兄られているとする。恓心中心 1 点の高温点温 度差 $\Delta t_{H S}=1,944.6^{\circ} \mathrm{C}$ を越党ない確率は，(2)式加ら $\lambda=3$ が得られ $P=0.9987$ となる。また， $P=0.9987$ の確率で $\Delta t_{H S}$ を越えないためには，高温点㐿数を $F_{H S}=1.156$ にすればよい。次に炉心全体について考 えると，第 3 (c) 図加 $\ln P_{c} / 2 N=-1.9 \times 10^{-5}$ 少得占

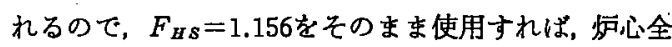
体の高温点が $\Delta t_{\boldsymbol{H} S}=1,944.6^{\circ} \mathrm{C}$ を越克ない確率は $P_{\mathrm{e}}=0.81$ Kなる。逆棌，炋心全体で $\Delta t_{\mathrm{H} s}=1,944.6^{\circ} \mathrm{C}$ を越えない確率を $P_{\mathrm{a}}=0.9987$ 亿するためには，第 4 図 (b)から $\lambda_{0}=4.23$ となるので，炻心中心の高温点係数を (2)式から $F_{H S}=1.220$ にしなけれぱならない。

\section{IV. 結 言}

複数個の高温点有する炉心の確率を考察し，次の ことを明らかにした。

(1) 同じ確率を有する複数個の高温点の確率を議論 し，高温点の数が多くなれば，める最大值を越兄 ない確率が低くなることを明らかにした。

（2） 月柱炉心の出力分布を $\Phi=\Phi_{0}\left\{1-(r / R)^{2}\right\}$ で表 わす時，高温点の確率解析法を導いた。そ結果 を設計に使用しやすい上5図式化した。

（3） 円柱炉心全体の高温点が，ある最大値を越えな い確率を99.87\%にするために情心中心の信頼 度を表方す係数 $\lambda_{0}$ は高温点数 $N$ との関係で与兄 られることを明らかにして，その結果を第 4 図(a)， (b)に示した。 


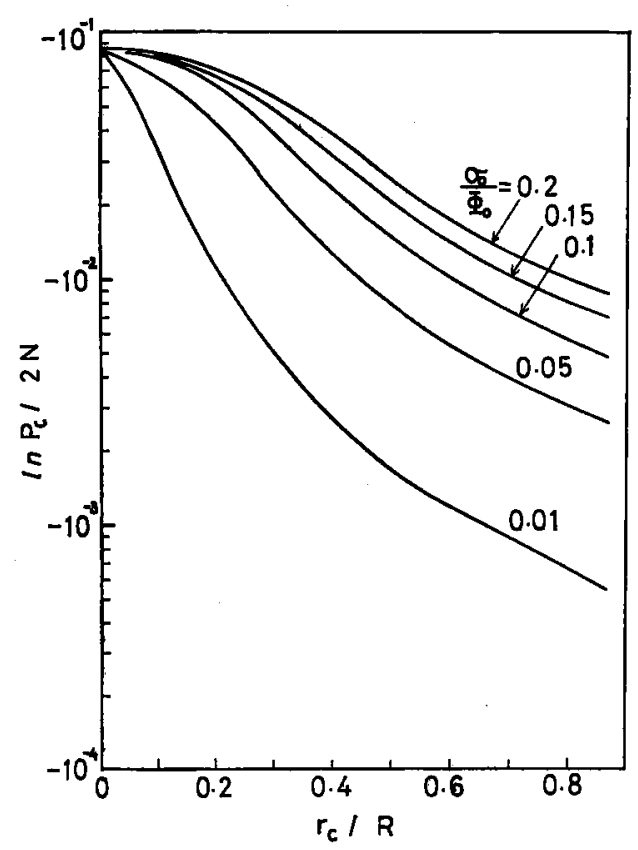

(a) $\lambda_{0}=1$

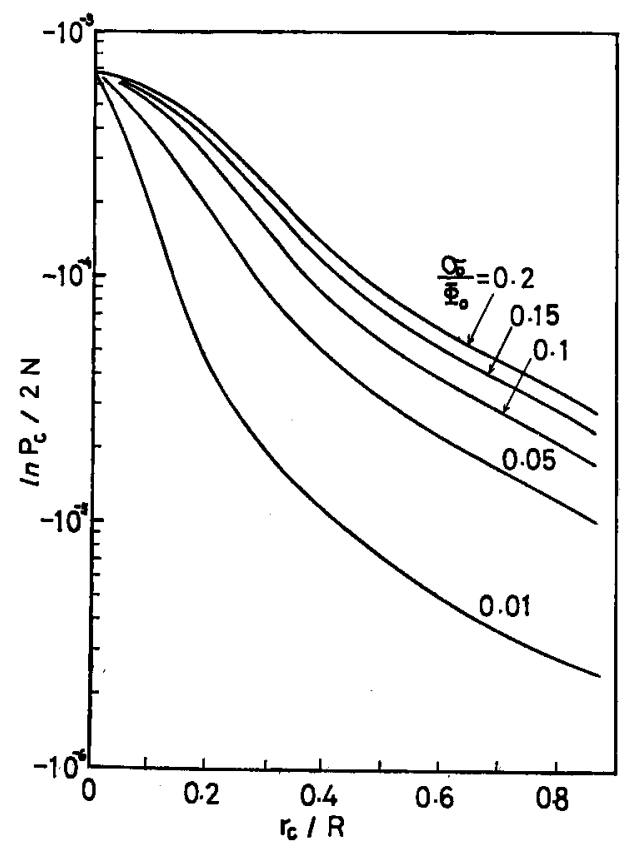

(c) $\lambda_{0}=3$

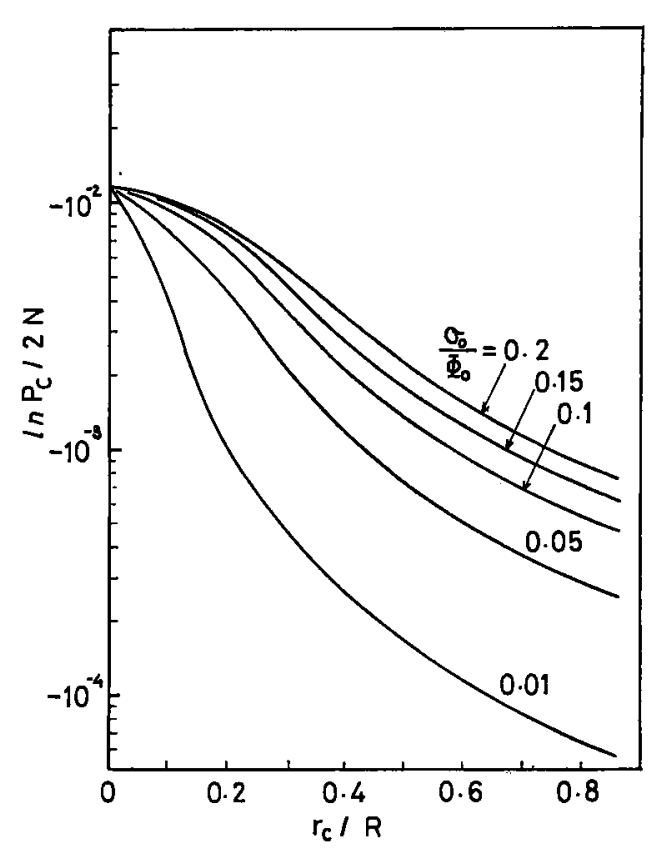

(b) $\lambda_{0}=2$

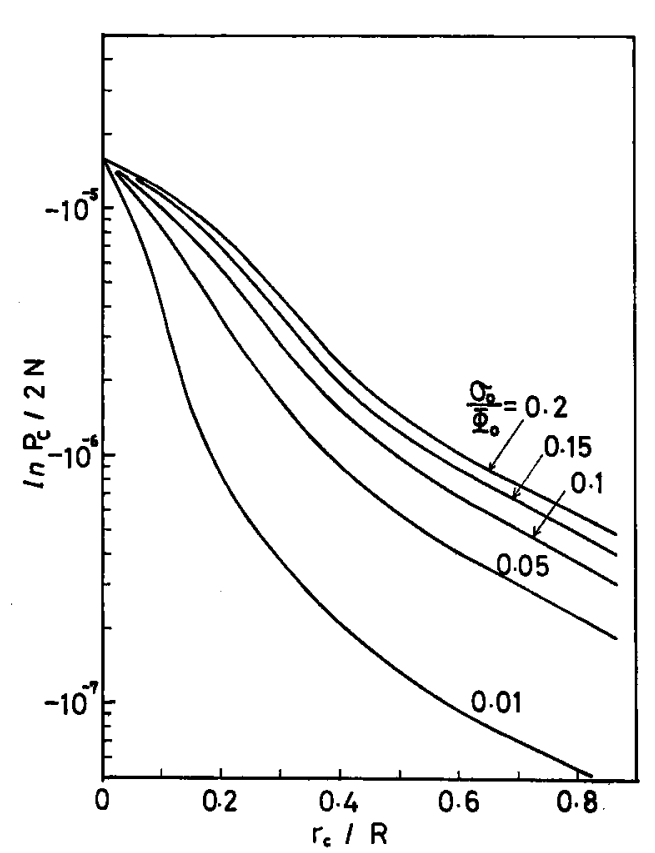

(d) $\lambda_{0}=4$

第 3 图 $r_{\mathrm{e}} / R$ と被数個の高温点との確率 


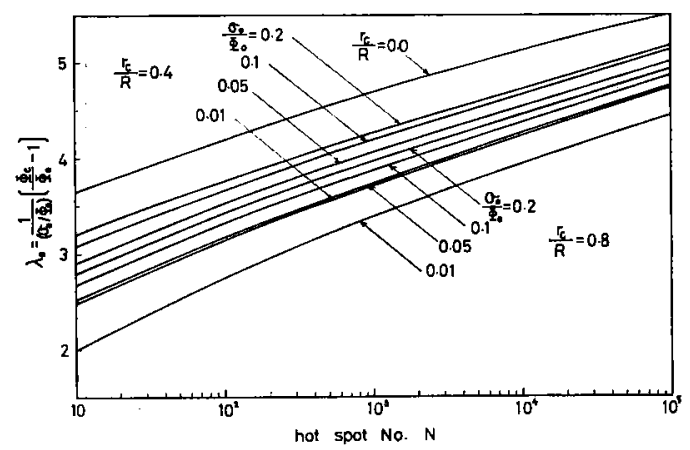

(a) $r_{\mathrm{c}} / R=0.4, \quad r_{\mathrm{c}} / R=0.8$

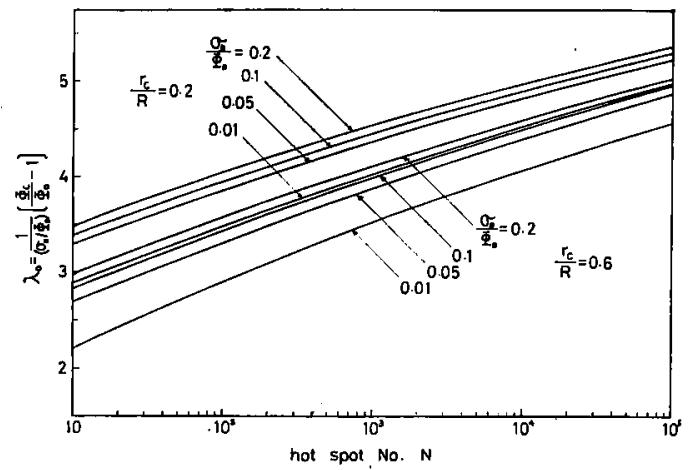

(b) $r_{t} / R=0.2, \quad r_{c} / R=0,6$

第 4 図炉心の確率が $P_{c}=0.9987$ 時の $N$ と $\lambda_{0}$ との関係

\section{一参考 文 献-...-}

(1) JUDGE, F.D., BOHL, L.S.: Effective hot-channel factors for "Flat" power reactors, Nucl. Sci. Eng., 28, 296 300 (1967).

(2) JUDGE, F.D.: A study concerning the number of "Effective" equally limiting hot channels in a reactor with a cosine power distribution, ibid., 31, 147 148 (1968).

(3) Amendola, A.: A statistical method for evaluation of hot channel factors in reactor design, $K F K-843$, (1968).

(4) 宮本喜戟：炉心熱設計に拈ける高温点係数と不確 かさの研究, 本 誌, 12〔4], 179〜186 (1970).

(5) HALD, A.: "Statistical Theory with Engineering Applications", pp. 10 (1962), John Wiley \& Sons.

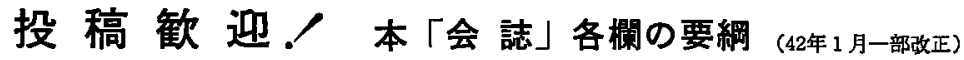

本誌各欄の内容は，大要つぎのとおりです。(有料分は6000円/頁)

(1) 研究論文(6面まで無料) 独創性のある, 結論の明確な，未発表の論文。欧文は「欧文誌」 に揭载される。

(2) 技 街 報 告(6頁まで無料) 施設・設備·装置等の建設・試験・運檕などの経験や結論をまとめ た実用的価值のある技術的論文。欧文は「欧文誌」に揭載。

(3) ショート・ノート 研究・技術上の新知見の速報，揭载論文に対する意見および質

(2 面まで無料) 疑応答(従来の寄書·討論を含む)。欧文は「欧文誌」に揭載。

(4) 資 料 (6頁まで無料) 研究・技術に関する参考資料拈よび解説・調查集計報告など。

(5)談話 室( 1 2 頁) 本会お゙よび本誌に対する希望・提言, おょび国際会境などの見 聞記・感想など。

(6) 巻頭言・総説·私のノートから·講演·討論会要旨·講座·新刊紹介等の各欄は編集委員会で企 画の上笴稿を依頼する。

会員投稿欗は，研究論文, 技術報告,ショートノート,凟料,談話室ですから，鹰ってご投稿願います。

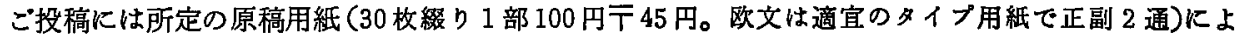
り，「投稿規程」に従って事務局宛ご送付下さい。その他，ご意見・ご希望やご提案は大倠迎です。 